\title{
Physiological characterization of thermotolerant yeast for cellulosic ethanol production
}

\author{
Daniela A. Costa $\cdot$ Carlos J. A. de Souza • Patrícia S. Costa • \\ Marina Q. R. B. Rodrigues • Ancély F. dos Santos • Mariana R. Lopes • \\ Hugo L. A. Genier • Wendel B. Silveira • Luciano G. Fietto
}

Received: 11 November 2013 /Revised: 24 January 2014 / Accepted: 28 January 2014 /Published online: 18 February 2014

(C) The Author(s) 2014. This article is published with open access at Springerlink.com

\begin{abstract}
The conversion of lignocellulose into fermentable sugars is considered a promising alternative for increasing ethanol production. Higher fermentation yield has been achieved through the process of simultaneous saccharification and fermentation (SSF). In this study, a comparison was performed between the yeast species Saccharomyces cerevisiae and Kluyveromyces marxianus for their potential use in SSF process. Three strains of S. cerevisiae were evaluated: two are widely used in the Brazilian ethanol industry (CAT-1 and PE-2), and one has been isolated based on its capacity to grow and ferment at $42{ }^{\circ} \mathrm{C}$ (LBM-1). In addition, we used thermotolerant strains of $K$. marxianus. Two strains were obtained from biological collections, ATCC 8554 and CCT 4086, and one strain was isolated based on its fermentative capacity (UFV-3). SSF experiments revealed that $S$. cerevisiae industrial strains (CAT-1 and PE-2) have the potential to produce cellulosic ethanol once ethanol had presented yields similar to yields from thermotolerant strains. The industrial strains are more tolerant to ethanol and had already been adapted to industrial conditions. Moreover, the study shows that although the $K$. marxianus strains have fermentative capacities similar to strains of $S$. cerevisiae, they have low tolerance to ethanol. This characteristic is an important target
\end{abstract}

D. A. Costa $\cdot$ H. L. A. Genier • W. B. Silveira

Departamento de Microbiologia (Department of Microbiology),

Universidade Federal de Viçosa, Av. PH Rolfs s/n, Campus

Universitário, 36571-000 Viçosa, MG, Brazil

D. A. Costa $\cdot$ C. J. A. de Souza $\cdot$ P. S. Costa $\cdot$

M. Q. R. B. Rodrigues · A. F. dos Santos • M. R. Lopes •

L. G. Fietto $(\square)$

Departamento de Bioquímica e Biologia Molecular (Department of

Biochemistry and Molecular Biology), Universidade Federal de

Viçosa, Av. PH Rolfs s/n, Campus Universitário, 36571-000 Viçosa,

MG, Brazil

e-mail: lgfietto@ufv.br for enhancing the performance of this yeast in ethanol production.

Keywords Simultaneous saccharification and fermentation . Ethanol $\cdot$ Sugarcane bagasse $\cdot$ Thermotolerant yeast

\section{Introduction}

The production of first-generation ethanol occurs from the fermentation of sugars derived from agricultural raw materials, mainly corn and sugarcane. The USA and Brazil are responsible for $70 \%$ of the world's production of ethanol fuel (Argueso et al. 2009).

According to the Brazil's National Company of Food and Supply (Companhia Nacional de Abastecimento (CONAB)), sugarcane production from the 2012/2013 harvest reached 602 million tonnes in Brazil, leading to the production of 39 million tonnes of sugar and 24 billion tonnes of ethanol. Because each tonne of sugarcane processed generates approximately 270-280 $\mathrm{kg}$ of bagasse, it can be extrapolated that 169 million tonnes of bagasse were produced (Canilha et al. 2012). Only one third of the biomass produced by the plant is used for sugar production, one third is bagasse, which is burnt to produce electricity, and the remaining one third is left in the field, which is decomposed by the microorganisms (Cortez et al. 2008). Thus, ethanol production would increase substantially if new technologies were developed to convert the polysaccharides from the leaves, straw, and bagasse, which represents approximately two thirds of the biomass, into fermentable sugars (Soccol et al. 2010).

The process of ethanol production from lignocellulosic wastes essentially consists of four stages: pretreatment, enzymatic hydrolysis, fermentation, and distillation (Sun and Cheng 2002; Tomas-Pejo et al. 2009). The traditional process of ethanol production from lignocellulosic biomass consists of 
a sequential process in which hydrolysis and fermentation are performed in different reactors. This process is known as separate hydrolysis and fermentation (SHF). An alternative to SHF is to perform hydrolysis and fermentation in the same bioreactor, a process known as simultaneous saccharification and fermentation (SSF) (Olofsson et al. 2008; Sanchez and Cardona 2008). The SSF process gives more attractive yields than the SHF process, with higher ethanol productivity and lower energy consumption. In SSF, the enzymes and microorganisms are added to the same reactor, allowing the monosaccharides released during enzymatic hydrolysis of biomass to be immediately converted into ethanol, and the continuous removal of monosaccharides from the medium minimizes the inhibition of enzymes by their products (Ballesteros et al. 2004; Olsson et al. 2006; Sanchez and Cardona 2008).

However, one of the major drawbacks of the SSF process is that enzymatic hydrolysis has an optimum temperature of approximately $50{ }^{\circ} \mathrm{C}$, while most fermentative microorganisms have optimum temperatures ranging between 30 and $37{ }^{\circ} \mathrm{C}$ (Abdel-Banat et al. 2010; Krishna et al. 2001). In this regard, an alternative to achieving the SSF process is to use thermotolerant fermentative microorganisms (Suryawati et al. 2008). There are several advantages associated with using thermotolerant yeasts, such as cost reduction associated with cooling fermentation vats, obtaining higher yields in saccharification, continuous removal of ethanol, and decreased risk of bacterial contamination (Banat et al. 1998; Limtong et al. 2007).

Strains of Saccharomyces cerevisiae, a traditional yeast for alcoholic fermentation, are widely used in the ethanol fuel industry. In Brazil, the strains most used by the Brazilian industries are PE-2, CAT-1 and BG-1 because they have remarkable capacities to compete with native strains and to survive and dominate during the industrial fermentation process. In the 2007/2008 crop period, the PE-2 and CAT-1 strains were used in approximately 150 distilleries, representing approximately $60 \%$ of the ethanol fuel produced in Brazil (Basso et al. 2008). Most S. cerevisiae strains are tolerant to low $\mathrm{pH}$ values, high concentrations of sugars, and ethanol compared to other species, which contributes to reducing the risk of contamination during industrial fermentation (Nevoigt 2008). However, the fermentation efficiency of S. cerevisiae at temperatures above $35{ }^{\circ} \mathrm{C}$ is low (Ohta et al. 1988). Accordingly, S. cerevisiae strains capable of fermenting at temperatures above $35{ }^{\circ} \mathrm{C}$ have been isolated, mainly from tropical regions (Banat et al. 1998; De Souza et al. 2012).

Among the yeasts used in industrial processes, Kluyveromyces marxianus has the best performance for growth and fermentation at temperatures above $35{ }^{\circ} \mathrm{C}$ (Abdel-Banat et al. 2010; Abdel-Fattah et al. 2000; Ballesteros et al. 2004; Banat et al. 1998; Hong et al. 2007; Nonklang et al. 2008; Singh et al. 1998; Suryawati et al. 2008; Wilkins et al. 2008). In addition, K. marxianus has other characteristics that are desirable in fermentation processes, such as high growth rates and the capacity to utilize a wide variety of substrates (Fonseca et al. 2008). In this context, this yeast species has been reported to be the most promising for use in SSF processes (Suryawati et al. 2008).

Recently, (De Souza et al. (2012)) have demonstrated the potential of the $S$. cerevisiae LBM1 strain to produce ethanol from sugarcane bagasse by the SSF process.

Considering that the tolerance of yeast to high temperatures and high concentrations of sugars and ethanol are desirable characteristics in industrial applications (Banat et al. 1992), the influence of these factors on the growth of six strains of yeasts was evaluated in this study: three strains of $S$. cerevisiae, two of which are widely used in the Brazilian ethanol industry (CAT-1 and PE-2) (Basso et al. 2008) and one strain isolated based on its capacity to grow and ferment at $42{ }^{\circ} \mathrm{C}$ (LBM-1) (De Souza et al. 2012); and three strains of K. marxianus, of which two were obtained from biological collections, ATCC 8554 and CCT 4086, and one strain was isolated because of its fermentative capacity (UFV-3) (De Souza et al. 2012; Diniz et al. 2012; Dos Santos et al. 2013; Silveira et al. 2005). In addition, the performances of these six strains of yeast in the production of ethanol from sugarcane bagasse in an SSF process were compared.

\section{Materials and methods}

Strains and culture media

The yeast strains used in this study are listed in Table 1. The culture medium used for maintenance and activation was YPD [ $2 \%$ yeast extract, $1 \%$ peptone, and $2 \%$ glucose $(w / v)$ ]; for solid medium, $2 \%(w / v)$ agar was added. All strains were stored and maintained in $20 \%$ glycerol at $-80{ }^{\circ} \mathrm{C}$.

\section{Culturing conditions in solid media}

Strains of $S$. cerevisiae (LBM-1, CAT-1, and PE-2) and K. marxianus (UFV-3, ATCC 8554 and CCT 4086) were previously grown in $2 \%$ YPD medium with agitation at $180 \mathrm{rpm}$ at $28^{\circ} \mathrm{C}$ for testing tolerance to temperature, ethanol, and glucose concentrations. Serial dilutions $(1: 1,1: 10$, and $1: 100)$ were prepared in saline solution $(0.85 \% \mathrm{NaCl})$ from cultures with optical densities (O.D.600 nm) of 0.5. A volume of $5 \mu \mathrm{l}$ of each dilution of culture was applied onto solid YPD plates. The tests were conducted on plates with different concentrations of carbon source $(2,4,8$, and $16 \%$ glucose) and in the presence or absence of ethanol $(2,4,6$, and $8 \%$ ethanol in $4 \%$ YPD). Plates were sealed with Parafilm and were incubated at $28,37,42$, and $45^{\circ} \mathrm{C}$ for $72 \mathrm{~h}$. 
Table 1 Strains of yeasts used

\begin{tabular}{|c|c|c|c|}
\hline Yeast strain & Genotype & Source & Strain designations \\
\hline $\begin{array}{l}\text { Saccharomyces cerevisiae } \\
\text { LBM-1 }\end{array}$ & Wild type & $\begin{array}{l}\text { Laboratório Biotecnologia Molecular-DBB/ } \\
\text { UFV }\end{array}$ & $\begin{array}{l}\text { UFMG-CM-Y342-Centro de Coleções Taxonômicas da } \\
\text { UFMG }\end{array}$ \\
\hline $\begin{array}{l}\text { Saccharomyces cerevisiae } \\
\text { CAT-1 }\end{array}$ & $\begin{array}{c}\text { Industrial } \\
\text { strain }\end{array}$ & Fermentec-Piracicaba - Brazil & $\begin{array}{l}\text { CBMAI 0957-Coleção Brasileira de Micro-organismos de } \\
\text { Ambiente e Indústria }\end{array}$ \\
\hline $\begin{array}{l}\text { Saccharomyces cerevisiae } \\
\quad \text { PE-2 }\end{array}$ & $\begin{array}{l}\text { Industrial } \\
\text { strain }\end{array}$ & Fermentec-Piracicaba-Brazil & $\begin{array}{l}\text { CBMAI 0959-Coleção Brasileira de Micro-organismos de } \\
\text { Ambiente e Indústria }\end{array}$ \\
\hline $\begin{array}{l}\text { Kluyveromyces marxianus } \\
\text { UFV-3 }\end{array}$ & Wild type & $\begin{array}{l}\text { Laboratório de Fisiologia de Micro- } \\
\text { organismos UFV }\end{array}$ & - \\
\hline $\begin{array}{l}\text { Kluyveromyces marxianus } \\
\text { ATCC } 8554\end{array}$ & Wild type & American Type Culture Collection & CBS $5795=$ NRRL Y-1109 = ATCC 8554 \\
\hline $\begin{array}{l}\text { Kluyveromyces marxianus } \\
\text { CCT } 4086\end{array}$ & Wild type & $\begin{array}{l}\text { Coleção de Culturas Tropicais-André Tosello } \\
\text { Tropical Culture }\end{array}$ & CBS 397 = NRRL Y-2415 = ATCC 46537 \\
\hline
\end{tabular}

Culturing conditions in liquid media

Tests of tolerance to temperature, ethanol, and glucose concentrations were performed in 96-well microplates incubated under agitation in a Versamax apparatus (Molecular Devices microplate reader). Strains of $S$. cerevisiae (LBM-1, CAT-1, and PE-2) and $K$. marxianus (UFV-3, ATCC 8554, and CCT 4086) were previously grown in $2 \%$ YPD medium under agitation at $180 \mathrm{rpm}$ at $28{ }^{\circ} \mathrm{C}$. From the preinoculums, dilutions were made in saline solution to an initial O.D. $600 \mathrm{~nm}$ of 0.1 . Each strain was inoculated in a final volume of $200 \mu \mathrm{l}$ of medium, and each test was performed in triplicate. Tests for growth were performed at different glucose concentrations (2, 4,8 , and $16 \%$ ) and in the presence or absence of ethanol (ethanol 2, 4, 6, and $8 \%$ in $4 \%$ YPD medium). The plates were sealed using plastic (Axygen Platemax Axysel sealing film) and incubated in the reader at temperatures of 28, 37, 42, and $45^{\circ} \mathrm{C}$ for $16 \mathrm{~h}$. Data were collected using the SoftMax Pro 5.3 program installed on the Versamax reader.

The specific growth rate of culture on each substrate was determined by linear regression of the values obtained by the Napierian logarithm of the O.D. $600 \mathrm{~nm}$ during the exponential growth phase, using at least five points of a plot of O.D. $600 \mathrm{~nm}$ versus time. The specific growth rate $(\mu)$ is the slope of the line obtained by regression.

\section{Fermentation tests}

Fermentation tests were performed at 37 and $42^{\circ} \mathrm{C}$ using glucose and pretreated sugarcane bagasse as substrates. Yeasts were preactivated in $50-\mathrm{mL}$ Erlenmeyer flasks containing $20 \mathrm{~mL}$ minimal media: $50 \mathrm{mM}$ citrate buffer, $\mathrm{pH} 4.8$; yeast extract $\left(2.5 \mathrm{~g} \mathrm{~L}^{-1}\right)$; peptone $\left(2.5 \mathrm{~g} \mathrm{~L}^{-1}\right) ; \mathrm{NH}_{4} \mathrm{Cl}\left(2 \mathrm{~g} \mathrm{~L}^{-1}\right)$; $\mathrm{KH}_{2} \mathrm{PO} 4\left(1 \mathrm{~g} \mathrm{~L}^{-1}\right) ; \mathrm{MgSO}_{4} .7 \mathrm{H}_{2} \mathrm{O}\left(0.3 \mathrm{~g} \mathrm{~L}^{-1}\right)$ with added glucose $\left(20 \mathrm{~g} \mathrm{~L}^{-1}\right)$ with agitation at $180 \mathrm{rpm}$ for $16 \mathrm{~h}$ at
$28{ }^{\circ} \mathrm{C}$. Fermentation tests were then conducted in $125-\mathrm{mL}$ Erlenmeyer flasks containing $50 \mathrm{~mL}$ of minimal medium supplemented with $4 \%(w / v)$ glucose. Cell cultures were inoculated with an initial O.D. $600 \mathrm{~nm}$ of 2 , and the test was conducted at 37 and $42{ }^{\circ} \mathrm{C}$ for $12 \mathrm{~h}$ at $180 \mathrm{rpm}$.

SSF tests were conducted in accordance with the parameters established by (De Souza et al. 2012). SSF experiments were conducted in $125-\mathrm{mL}$ Erlenmeyer flasks each containing $50 \mathrm{~mL}$ of minimal medium without glucose, as described above, with agitation at $180 \mathrm{rpm}$. The solid fraction obtained from pretreatment was used as the substrate at $8 \%(w / v)$ concentration. Initially, a presaccharification was made for $72 \mathrm{~h}$ at $50{ }^{\circ} \mathrm{C}$ using commercial enzyme (Celluclast $1.5 \mathrm{~L}$ ) at a concentration of 15 filter paper units (FPU) per gram of substrate. SSF tests were performed under sterile conditions, and fermentation was conducted at 37 and $42{ }^{\circ} \mathrm{C}$ using yeasts at an initial O.D.600 nm of 2. In both tests, fermentation samples were withdrawn at 2 -h intervals for subsequent determination of glucose and ethanol by high-performance liquid chromatography (HPLC). SSF tests were also conducted in bioreactor. By this purpose, the experiments were performed in a $1.3 \mathrm{~L}$ bioreactor (New Brunswick) containing $500 \mathrm{~mL}$ of minimal medium without glucose as described above, and $40 \mathrm{~g}$ of pretreated sugar cane bagasse. Initially, a prehydrolysis was carried out for $72 \mathrm{~h}$ at $50{ }^{\circ} \mathrm{C}$ using a commercial enzyme (Celluclast 1.5 L) $15 \mathrm{FPU}$ per gram of substrate. After this initial period, the fermentation was initiated using the strain of $S$. cerevisiae CAT-1. This step was conducted at $37^{\circ} \mathrm{C}$ and aliquots were collected for analysis of glucose and ethanol by HPLC.

\section{Fermentation parameters}

The ethanol yield $\left(Y_{\mathrm{E} / \mathrm{B}}\right)$ was calculated at the end $(8 \mathrm{~h})$ of fermentation by dividing the difference between the final 
$\left(\mathrm{EtOH}_{\mathrm{f}}\right)$ and initial $\left(\mathrm{EtOH}_{\mathrm{i}}\right)$ ethanol masses (in grams) by the initial pretreated biomass (in grams):

$Y_{\mathrm{E} / \mathrm{B}}=\frac{\mathrm{EtOH}_{\mathrm{f}}-\mathrm{EtOH}_{\mathrm{i}}}{\text { Biomass }}$

The ethanol yield $\left(Y_{\mathrm{E} / \mathrm{G}}\right)$ was calculated at the end $(8 \mathrm{~h})$ of fermentation by dividing the difference between the final $\left(\mathrm{EtOH}_{\mathrm{f}}\right)$ and initial $\left(\mathrm{EtOH}_{\mathrm{i}}\right)$ ethanol masses (in grams) by difference between the final $\left(\mathrm{Glu}_{\mathrm{f}}\right)$ and initial $\left(\mathrm{Glu}_{\mathrm{i}}\right)$ glucose masses:

$Y_{\mathrm{E} / \mathrm{G}}=\frac{\mathrm{EtOH}_{\mathrm{f}}-\mathrm{EtOH}_{\mathrm{i}}}{\mathrm{Glu}_{\mathrm{f}}-\mathrm{Glu}_{\mathrm{i}}}$

\section{Analytical methods}

Cell density was measured by turbidity at $600 \mathrm{~nm}$. To determine the concentrations of ethanol and sugar in the culture media, samples were collected and subjected to centrifugation. The supernatant was kept at $-20{ }^{\circ} \mathrm{C}$ for analysis. Quantitative analysis of sugars and ethanol were conducted by HPLC using an Aminex HPX-87H (Bio-Rad) ion exchange column maintained at $60{ }^{\circ} \mathrm{C}$. The eluent for the separation was $5 \mathrm{mM}$ sulfuric acid, applied at an elution rate of $0.7 \mathrm{~mL} \mathrm{~min}^{-1}$. The column was attached to an HP 1047 A refractive index detector.

\section{Results}

Temperature and glucose concentrations effects on the growth of $K$. marxianus and $S$. cerevisiae strains

To analyze the temperature and the concentrations of sugars and ethanol effects on the growth of yeasts, initial tests were performed on solid media at different glucose concentrations $(2,4,8$, and $16 \% \mathrm{w} / \mathrm{v})$ under different temperatures $(30,37$, 42 , and $45^{\circ} \mathrm{C}$ ). As shown in Table 2 , the tested strains grew in all dilutions and in all concentrations of glucose up to $42{ }^{\circ} \mathrm{C}$. At $45^{\circ} \mathrm{C}$, the $K$. marxianus strains grew in the four glucose concentrations tested, while the $S$. cerevisiae strains were able to grow only in media containing glucose concentrations of 8 and $16 \%(w / v)$ (Table 2).

The inhibitory effect of ethanol on yeast growth was evaluated at different temperatures. As illustrated in Table 3, the stress caused by ethanol in yeasts was more drastic than the one caused by variations in glucose concentration. At $30{ }^{\circ} \mathrm{C}$, S. cerevisiae strains exhibited good growth in up to $8 \%(\mathrm{v} / \mathrm{v})$ ethanol and weak growth at $10 \%(\mathrm{v} / \mathrm{v})$ ethanol, while the $K$. marxianus strains only grew up to a concentration of $6 \%$ (v/v) ethanol. However, the tolerance of the $S$. cerevisiae strains to ethanol decreased with increasing temperature. At $30{ }^{\circ} \mathrm{C}$, ethanol tolerance was $10 \%(\mathrm{v} / \mathrm{v})$, and it decreased to $4 \%(\mathrm{v} / \mathrm{v})$ at $42{ }^{\circ} \mathrm{C}$. For $K$. marxianus, the increase in temperature also reduced ethanol tolerance, but the effect was less drastic than for $S$. cerevisiae. At $30^{\circ} \mathrm{C}$, the ethanol tolerances for $S$. cerevisiae and $K$. marxianus strains were $10 \%$ and $6 \%$ (v/v), respectively, while at $42{ }^{\circ} \mathrm{C}$, the tolerance was $4 \%(\mathrm{v} / \mathrm{v})$ for both.

To evaluate the growth of yeast in liquid medium, yeasts were exposed to thermal, osmotic, and ethanol stresses, and their growth was monitored for $16 \mathrm{~h}$. Figure 1 represents the growth of $S$. cerevisiae strains at different concentrations of glucose at different temperatures.

When evaluating the effects of glucose concentration on growth, it was noted that $S$. cerevisiae strains were not dramatically affected by increased glucose concentrations, but $K$. marxianus strains showed less growth in $16 \%$ glucose $(w /$ v) (Fig. 2b) compared to $S$. cerevisiae strains (Fig. 1b). The high glucose concentrations effects was higher for $K$. marxianus CCT 4086, for which the lag phase increased; additionally, a maximum O.D.600 nm of $0.78 \pm 0.038$ was attained, compared with O.D.600 nm values of 1.0 to 1.5 for the other strains (Table 4).

Regarding temperature, at $42{ }^{\circ} \mathrm{C}$ (Fig. 2c), K. marxianus strains grew better in relation to the $S$. cerevisiae strains (Fig. 1c), confirming the already described thermotolerance

Table 2 Growth evaluation of yeast strains in YP medium containing different concentrations of glucose $(2,4,8$, and $16 \% w / v)$ and at different temperatures, with $(++++)$ good growth, $(++)$ average growth, $(+)$ weak growth, $(-)$ no growth

\begin{tabular}{|c|c|c|c|c|c|c|c|c|c|c|c|c|c|c|c|c|}
\hline \multirow[t]{2}{*}{ Yeast strain } & \multicolumn{4}{|c|}{$30{ }^{\circ} \mathrm{C}$} & \multicolumn{4}{|c|}{$37^{\circ} \mathrm{C}$} & \multicolumn{4}{|c|}{$42{ }^{\circ} \mathrm{C}$} & \multicolumn{4}{|c|}{$45^{\circ} \mathrm{C}$} \\
\hline & $2 \%$ & $4 \%$ & $8 \%$ & $16 \%$ & $2 \%$ & $4 \%$ & $8 \%$ & $16 \%$ & $2 \%$ & $4 \%$ & $8 \%$ & $16 \%$ & $2 \%$ & $4 \%$ & $8 \%$ & $16 \%$ \\
\hline S. cerevisiae LBM-1 & +++ & +++ & +++ & +++ & +++ & +++ & +++ & +++ & +++ & +++ & +++ & +++ & - & + & +++ & +++ \\
\hline S. cerevisiae CAT-1 & +++ & +++ & +++ & +++ & +++ & +++ & +++ & +++ & +++ & +++ & +++ & +++ & - & - & ++ & +++ \\
\hline S. cerevisiae PE-2 & +++ & +++ & +++ & +++ & +++ & +++ & +++ & +++ & +++ & +++ & +++ & +++ & - & - & ++ & +++ \\
\hline K. marxianus UFV-3 & +++ & +++ & +++ & +++ & +++ & +++ & +++ & +++ & +++ & +++ & +++ & +++ & +++ & +++ & +++ & +++ \\
\hline K. marxianus ATCC 8554 & +++ & +++ & +++ & +++ & +++ & +++ & +++ & +++ & +++ & +++ & +++ & +++ & +++ & +++ & +++ & +++ \\
\hline K. marxianus CCT 4086 & +++ & +++ & +++ & +++ & +++ & +++ & +++ & +++ & +++ & +++ & +++ & +++ & +++ & +++ & +++ & +++ \\
\hline
\end{tabular}


Table 3 Growth evaluation of yeast strains in $4 \%$ YPD medium containing different concentrations of ethanol $(2,4,6,8$, and $10 \% \mathrm{v} / \mathrm{v})$ and at different temperatures, with $(++++)$ good growth, $(++)$ average growth, $(+)$ weak growth, $(-)$ no growth

\begin{tabular}{|c|c|c|c|c|c|c|c|c|c|c|c|c|c|c|c|c|c|c|c|c|}
\hline \multirow[t]{2}{*}{ Yeast strain } & \multicolumn{5}{|c|}{$30{ }^{\circ} \mathrm{C}$} & \multicolumn{5}{|c|}{$37{ }^{\circ} \mathrm{C}$} & \multicolumn{5}{|c|}{$42^{\circ} \mathrm{C}$} & \multicolumn{5}{|c|}{$45^{\circ} \mathrm{C}$} \\
\hline & $2 \%$ & $4 \%$ & $6 \%$ & $8 \%$ & $10 \%$ & $2 \%$ & $4 \%$ & $6 \%$ & $8 \%$ & $10 \%$ & $2 \%$ & $4 \%$ & $6 \%$ & $8 \%$ & $10 \%$ & $2 \%$ & $4 \%$ & $6 \%$ & $8 \%$ & $10 \%$ \\
\hline S. cerevisiae LBM-1 & +++ & +++ & +++ & +++ & + & +++ & +++ & +++ & ++ & - & +++ & +++ & - & - & - & +++ & - & - & - & - \\
\hline S. cerevisiae CAT-1 & +++ & +++ & +++ & +++ & + & +++ & +++ & +++ & +++ & - & +++ & +++ & - & - & - & +++ & - & - & - & - \\
\hline S. cerevisiae $\mathrm{PE}-2$ & +++ & +++ & +++ & +++ & + & +++ & +++ & +++ & ++ & - & +++ & +++ & - & - & - & +++ & - & - & - & - \\
\hline K. marxianus UFV-3 & +++ & +++ & +++ & - & - & +++ & +++ & - & - & - & +++ & + & - & - & - & +++ & - & - & - & - \\
\hline $\begin{array}{l}\text { K. marxianus ATCC } \\
8554\end{array}$ & +++ & +++ & +++ & + & - & +++ & +++ & - & - & - & +++ & +++ & - & - & - & +++ & +++ & - & - & - \\
\hline $\begin{array}{l}\text { K. marxianus CCT } \\
4086\end{array}$ & +++ & +++ & +++ & - & - & +++ & +++ & - & - & - & +++ & +++ & - & - & - & +++ & +++ & - & - & - \\
\hline
\end{tabular}

of $K$. marxianus. S. cerevisiae strains LBM-1 and CAT-1 did not grow at $42{ }^{\circ} \mathrm{C}$ in $2 \%(w / v)$ glucose (Fig. 1c); growth only occurred in glucose concentrations above $2 \%(w / v)$. $S$. cerevisiae PE-2 grew less compared to the LBM-1 and CAT-1 strains under the same conditions.
At $45^{\circ} \mathrm{C}$ (Fig. 2d), K. marxianus strains grew at different concentrations of glucose, while $S$. cerevisiae strains did not grow in the glucose concentrations tested. For K. marxianus UFV-3, the same phenomenon was observed for $S$. cerevisiae LBM-1 and S. cerevisiae CAT-1, i.e., higher glucose
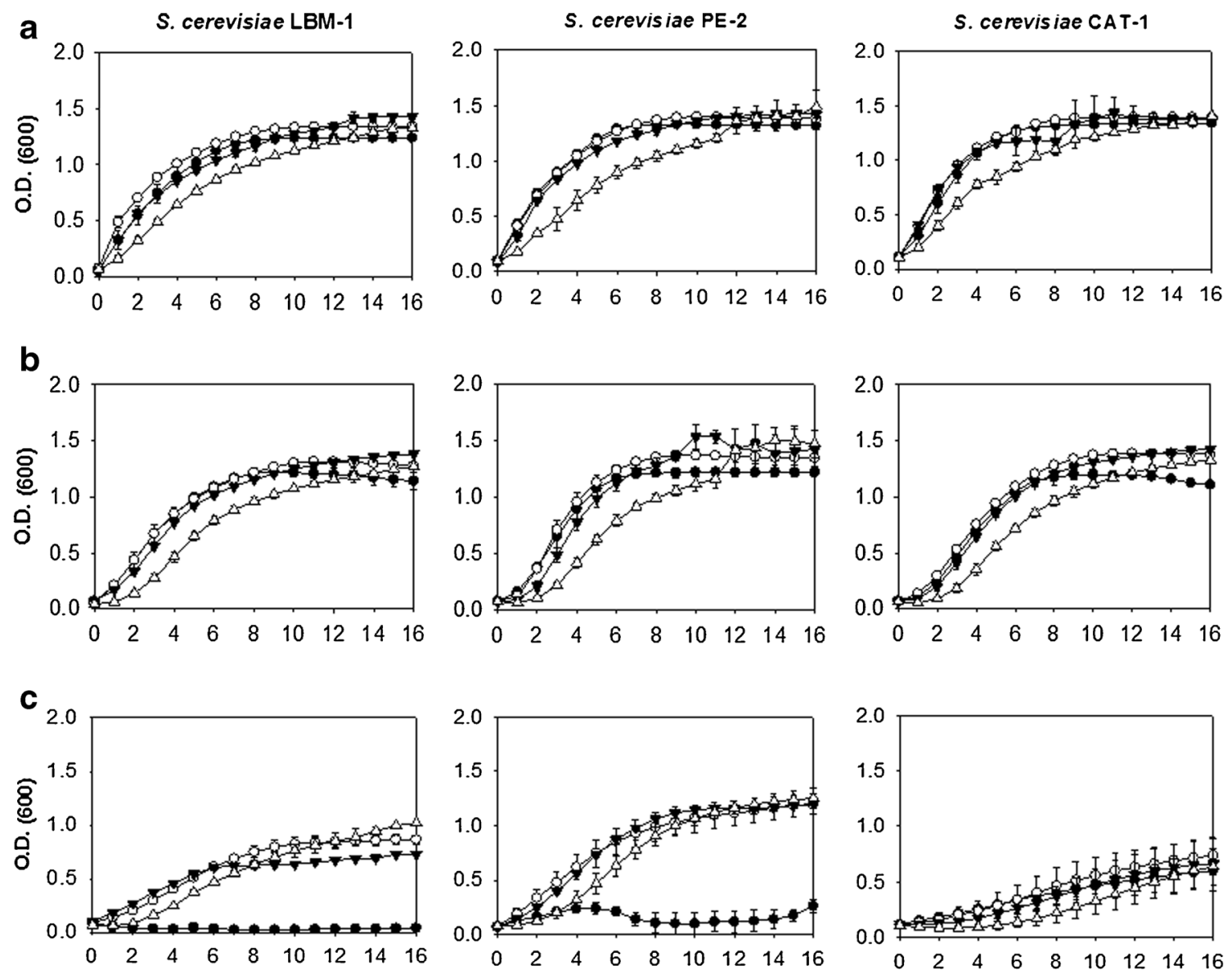

Fig. 1 Growth curves of $S$. cerevisiae strains as a function of varying temperature and glucose concentrations in the liquid YP medium. Each column represents a strain, LBM-1, PE-2, and CAT-1, as shown in the figure. Each line represents a specific growth temperature. a $30^{\circ} \mathrm{C}$. b

$37^{\circ} \mathrm{C}$. $42{ }^{\circ} \mathrm{C}$. The symbols represent the concentration of glucose added to the liquid culture medium: (black circle) $2 \%$ glucose, (white circle) $4 \%$ glucose, (black down-pointing triangle) $8 \%$ glucose and (white triangle) $16 \%$ glucose 

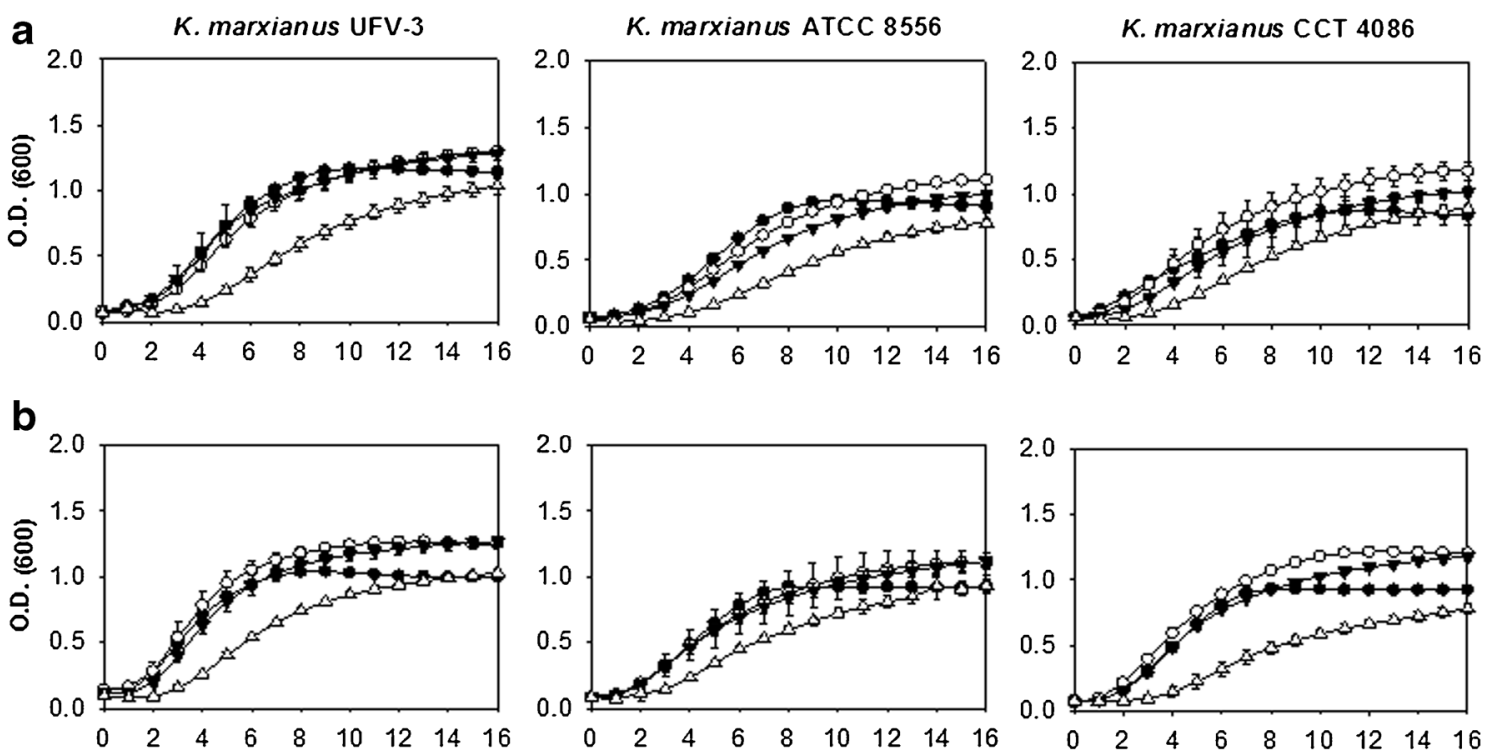

C
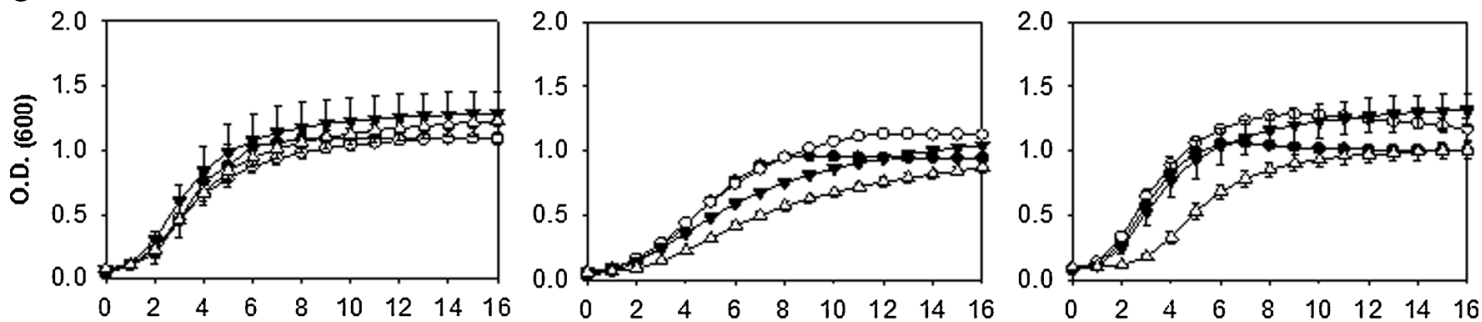

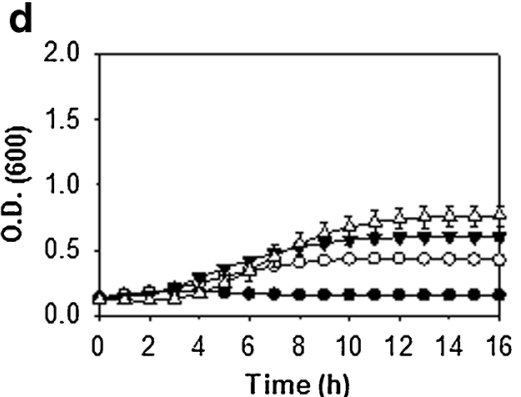

Fig. 2 Growth curves of $K$. marxianus strains as a function of varying temperature and glucose concentrations in the liquid YP medium. Each column represents a strain, UFV-3, ATCC 8554, and CCT 4086, as shown in the figure. Each line represents a specific growth temperature. a $30^{\circ} \mathrm{C}$,

concentrations seemed to protect the cells from stress caused by increased temperature.

To verify the strains' thermotolerance capacities, a comparison of the specific growth rates $(\mu)\left(\mathrm{h}^{-1}\right)$ was made at different temperatures. For calculation of the $\mu$ values, a glucose concentration of $4 \%(w / v)$ was chosen, as the strains showed better growth at different temperatures at that concentration.

As noted in Table 4, the specific growth rates of S. cerevisiae strains at $30{ }^{\circ} \mathrm{C}$ were similar. At a temperature of $37^{\circ} \mathrm{C}$, S. cerevisiae CAT-1 and S. cerevisiae PE-2 had the greatest $\mu$ values compared to LBM-1: 0.368 and 0.318 , respectively. At $42{ }^{\circ} \mathrm{C}$, the three $S$. cerevisiae strains grew similarly. At $45{ }^{\circ} \mathrm{C}$, the growth of $S$. cerevisiae strains decreased substantially; the only strain that still showed growth was $S$. cerevisiae LBM-1. With these data, it can be concluded that the maximum tolerated temperature under the conditions tested for $S$. cerevisiae strains was $42{ }^{\circ} \mathrm{C}$. Another fact to be noted was the more thermotolerant behavior of the $S$. cerevisiae LBM-1 strain.

The growth rates of $K$. marxianus were much higher than those of $S$. cerevisiae (Table 4). K. marxianus UFV-3 had similar $\mu$ values for temperatures of 30,37 , and $42^{\circ} \mathrm{C}$, while the growth rate decreased at $45{ }^{\circ} \mathrm{C}$. However, the biological collection K. marxianus strains ATCC 8554 and CCT 4086 had similar $\mu$ values. These thermotolerance data are 
Table 4 Specific growth rates $(\mu)$ and maximum O.D.600 nm values in microplates containing $4 \%$ YPD medium at different temperatures

\begin{tabular}{|c|c|c|c|c|c|c|c|c|}
\hline \multirow[t]{2}{*}{ Yeast strain } & \multicolumn{4}{|c|}{$\mu$ value $\left(\mathrm{h}^{-1}\right)$} & \multicolumn{4}{|c|}{ O.D.(600) } \\
\hline & $30^{\circ} \mathrm{C}$ & $37^{\circ} \mathrm{C}$ & $42{ }^{\circ} \mathrm{C}$ & $45^{\circ} \mathrm{C}$ & $30{ }^{\circ} \mathrm{C}$ & $37^{\circ} \mathrm{C}$ & $42{ }^{\circ} \mathrm{C}$ & $45^{\circ} \mathrm{C}$ \\
\hline LBM-1 & 0.13 & 0.22 & 0.27 & 0.11 & 1.18 & 1.08 & 0.61 & 0.15 \\
\hline CAT-1 & 0.18 & 0.37 & 0.23 & 0.03 & 1.28 & 1.24 & 0.86 & 0.15 \\
\hline PE-2 & 0.15 & 0.32 & 0.20 & 0.06 & 1.27 & 1.10 & 0.34 & 0.13 \\
\hline UFV-3 & 0.46 & 0.40 & 0.38 & 0.17 & 0.79 & 1.05 & 0.87 & 0.34 \\
\hline ATCC 8554 & 0.41 & 0.39 & 0.38 & 0.32 & 0.56 & 0.72 & 0.75 & 0.63 \\
\hline ССТ 4086 & 0.36 & 0.35 & 0.38 & 0.33 & 0.73 & 0.89 & 1.17 & 0.68 \\
\hline
\end{tabular}

consistent with the literature because it has already been demonstrated that $K$. marxianus grows rapidly, even at temperatures above $40^{\circ} \mathrm{C}$ (Fonseca et al. 2008).

Ethanol effects on the growth of $K$. marxianus and $S$. cerevisiae strains

Figures 3 and 4 represent the growth variations of the strains tested in different concentrations of ethanol: $2,4,6$, and $8 \%$ (v/v). S. cerevisiae strains tolerated ethanol to concentrations up to $8 \%(\mathrm{v} / \mathrm{v})$, and the newly isolated $S$. cerevisiae LBM-1 strain proved to be as tolerant to ethanol as the industrial strains S. cerevisiae CAT-1 and S. cerevisiae PE-2 (Fig. 3). However, $K$. marxianus had lower tolerances to ethanol: the $K$. marxianus biological collection strains ATCC 8554 and CCT 4086 tolerated higher concentrations of ethanol, up to $6 \%$ (v/v), than the $K$. marxianus UFV-3 strain, which grew only in concentrations up to $4 \%$ (v/v) ethanol (Fig. 4).

In Fig. 4b, it is shown that increasing the temperature to $37^{\circ} \mathrm{C}$ did not significantly change the growth of $S$. cerevisiae strains; however, when growth was assessed at the higher temperatures of $42{ }^{\circ} \mathrm{C}$ (Fig. 4c) and $45{ }^{\circ} \mathrm{C}$ (Fig. $4 \mathrm{~d}$ ), $S$. cerevisiae growth was reduced, and at $42{ }^{\circ} \mathrm{C}$, no strain was able to grow in the higher ethanol concentrations of 6 and $8 \%(\mathrm{v} / \mathrm{v})$. Therefore, tests at $45^{\circ} \mathrm{C}$ were not performed. The $K$. marxianus strains were less tolerant to ethanol compared with the $S$. cerevisiae strains.

\section{Fermentation tests}

The thermotolerance observed in the strains tested is of utmost importance in making the SSF process from sugarcane bagasse viable. Thus, two temperatures were selected-37 and $42{ }^{\circ} \mathrm{C}$, at which all of the tested strains were able to grow- to perform fermentation and SSF tests.

The fermentation potential of $S$. cerevisiae and $K$. marxianus was evaluated in fermentation medium with $4 \%(w / v)$ added glucose for $12 \mathrm{~h}$ at 37 and $42^{\circ} \mathrm{C}$ (Table 5). At $37^{\circ} \mathrm{C}$, S. cerevisiae and $K$. marxianus strains consumed all of the glucose present in the medium, producing $20 \mathrm{~g} \mathrm{~L}^{-1}$ of ethanol on average, resulting in similar fermentation yields for the strains at this temperature.

At $42{ }^{\circ} \mathrm{C}$, the strains showed similar behavior; however, residual glucose was higher for $S$. cerevisiae LBM-1, $S$. cerevisiae CAT-1, $S$. cerevisiae PE-2, and $K$. marxianus UFV-3, while $K$. marxianus ATCC 8554 and $K$. marxianus CCT 4086 consumed all of the glucose in the medium. The final production of ethanol was very similar for all strains, with higher values for $K$. marxianus ATCC 8554 and K. marxianus CCT 4086: $12.11 \mathrm{~g} \mathrm{~L}^{-1}$ and $12.06 \mathrm{~g} \mathrm{~L}^{-1}$ of ethanol, respectively (Table 5). The yield of ethanol at $42{ }^{\circ} \mathrm{C}$ was slightly higher for the $S$. cerevisiae yeast species than for the $K$. marxianus yeasts.

Simultaneous saccharification and fermentation test with sugarcane bagasse

Table 6 describes the concentrations and yields obtained by the SSF process at different temperatures for the strains analyzed. At both temperatures, the process yields were calculated in two different ways. The yield $Y_{\mathrm{E} / \mathrm{G}}$ is the function of the initial glucose concentration at the beginning of fermentation. The yield $Y_{\mathrm{E} / \mathrm{C}}$ is the function of the initial concentration of biomass in the presaccharification step. According to the $Y_{\mathrm{E} / \mathrm{G}}$ data obtained, it can be confirmed that these values were numerically larger than the theoretical yield of the process (0.51), confirming that the hydrolysis occurred simultaneously with fermentation during the process.

SSF tests at both 37 and $42{ }^{\circ} \mathrm{C}$ returned very similar $Y_{\mathrm{E} / \mathrm{C}}$ values. However, tests at $37^{\circ} \mathrm{C}$ showed a greater production of ethanol than tests at $42{ }^{\circ} \mathrm{C}$. The highest concentration of ethanol at $37{ }^{\circ} \mathrm{C}$ was $22.62 \mathrm{~g} \mathrm{~L}^{-1}$ for $K$. marxianus UFV-3, with a yield of 0.28 . At $42{ }^{\circ} \mathrm{C}$, the highest concentration of ethanol was $22.84 \mathrm{~g} \mathrm{~L}^{-1}$ for $S$. cerevisiae CAT-1, with a yield of 0.29 (Table 6). Further experiments were performed in bioreactors at $37{ }^{\circ} \mathrm{C}$, with the $S$. cerevisiae CAT-1 strain. The ethanol yield obtained $\left(Y_{\mathrm{E} / \mathrm{C}}=0.24\right)$ in bioreactor was similar to that obtained in Erlenmeyer flasks experiments $\left(Y_{\mathrm{E} / \mathrm{C}}=0.26\right)$. 


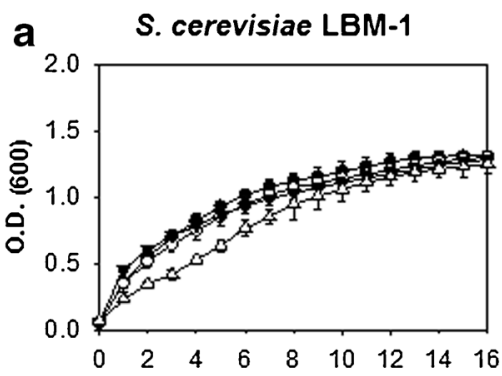

S. cerevisiae CAT-1

b

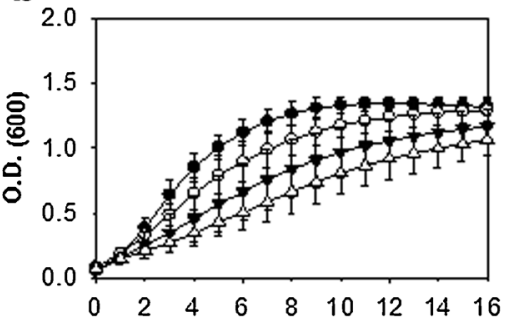

C

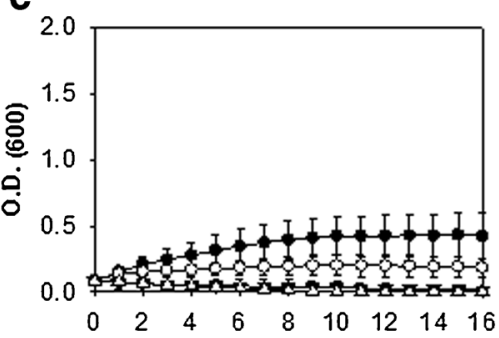

d

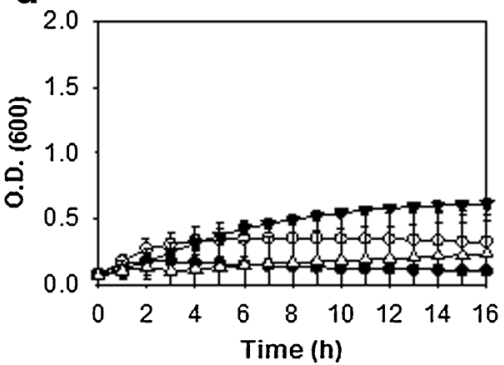

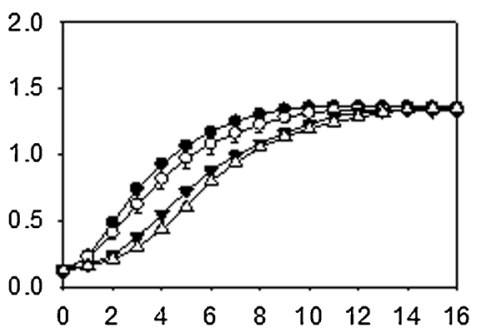

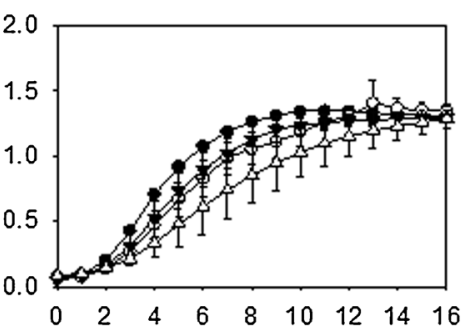

S. cerevisiae PE-2
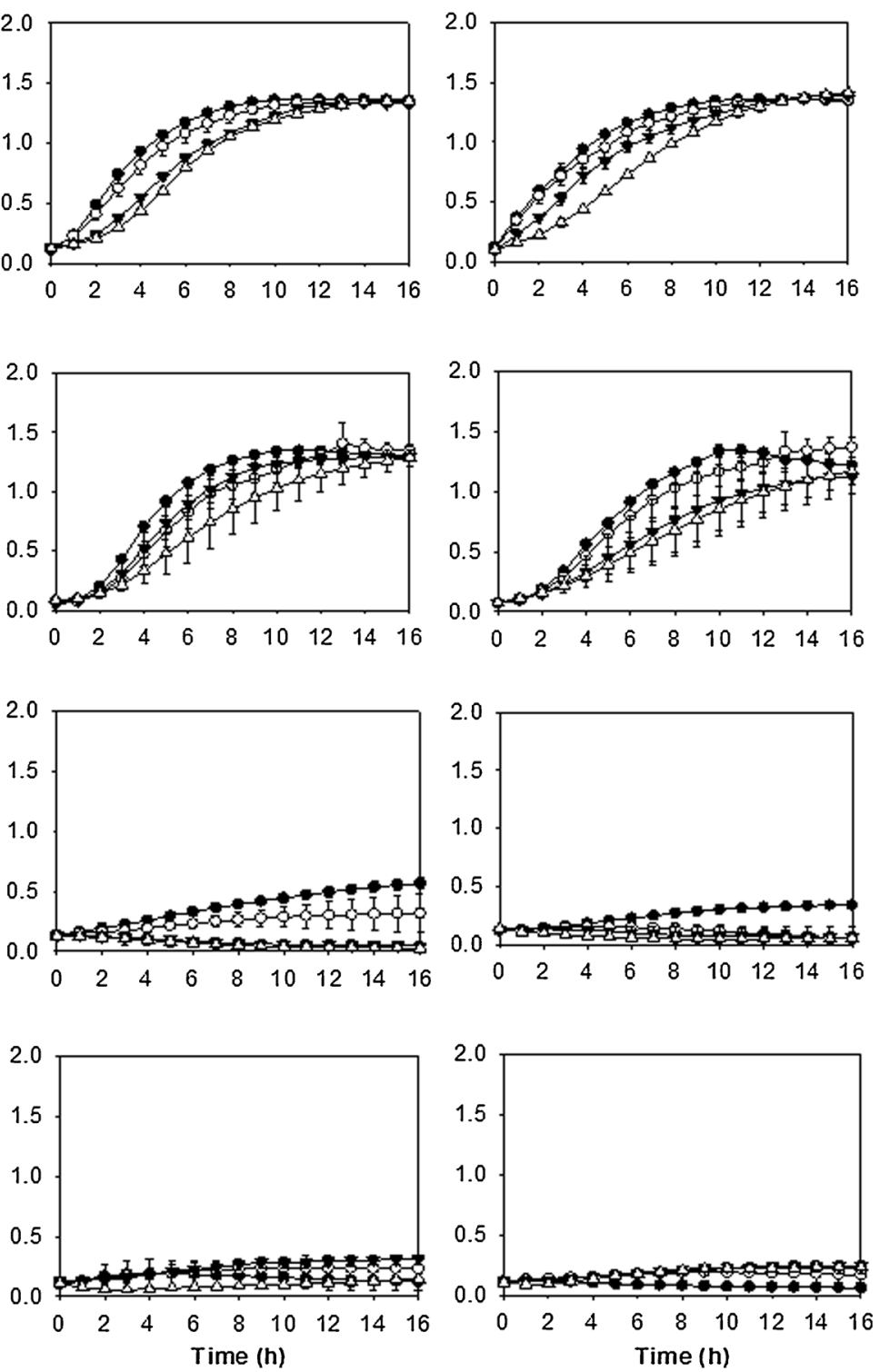

Fig. 3 Growth curves of $S$. cerevisiae strains as a function of varying temperature and ethanol concentrations in the liquid YP medium supplemented with $4 \%$ glucose (v/v). Each column represents a strain, LBM-1, PE-2, and CAT-1, as shown in the figure. Each line represents a specific

\section{Discussion}

Tolerance to high temperatures, ethanol and high concentrations of sugars are important features for microorganism producers of ethanol. Thus, the isolation and characterization of yeasts tolerant to these stresses are crucial to the development of processes for ethanol production from lignocellulosic biomass performed simultaneously (SSF) (Ballesteros et al. 2004; Olsson et al. 2006; Sanchez and Cardona 2008). To analyze the effects of temperature and high concentrations of glucose on the growth of yeasts that produce ethanol, experiments were performed under different physiological conditions with $S$. cerevisiae and $K$. marxianus strains. Only $K$. marxianus growth temperature. a $30{ }^{\circ} \mathrm{C}$. b $37^{\circ} \mathrm{C}$. c $42{ }^{\circ} \mathrm{C}$. d $45^{\circ} \mathrm{C}$. The symbols represent the concentration of ethanol added to the liquid culture medium: (black circle) $2 \%$ ethanol, (white circle) $4 \%$ ethanol, (black downpointing triangle) $6 \%$ ethanol, and (white triangle) $8 \%$ ethanol

strains were capable of growing in liquid media at $45^{\circ} \mathrm{C}$ (Fig. 2), showing the yeast species' greater tolerance to higher temperatures compared to $S$. cerevisiae (Abdel-Fattah et al. 2000; Ballesteros et al. 2004; Hong et al. 2007; Nonklang et al. 2008; Singh et al. 1998; Suryawati et al. 2008). At $45^{\circ} \mathrm{C}$, the $S$. cerevisiae strains grew on solid media only at 8 and $16 \%(w / v)$ glucose concentrations (Table 2). Two events may occur to explain this fact: one is "cross-tolerance", in which one type of stress confers partial protection against other stresses (Causton et al. 2001; Koedritha et al. 2008; Zakrzewska et al. 2011); the other event is the physical effect of glucose protecting cell membranes from the harmful effects of temperature. This effect of carbohydrates protecting cells 


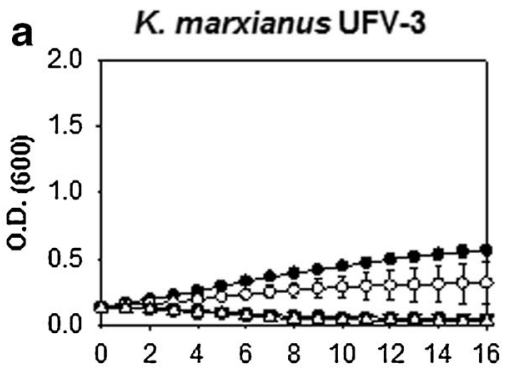

K. marxianus ATCC 8556

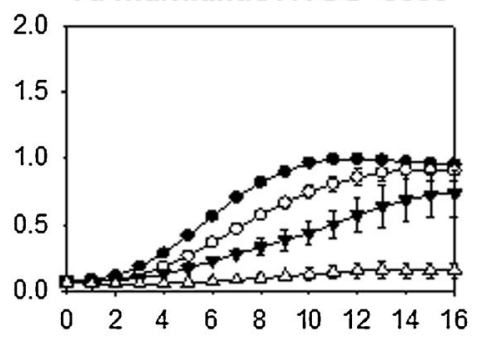

b
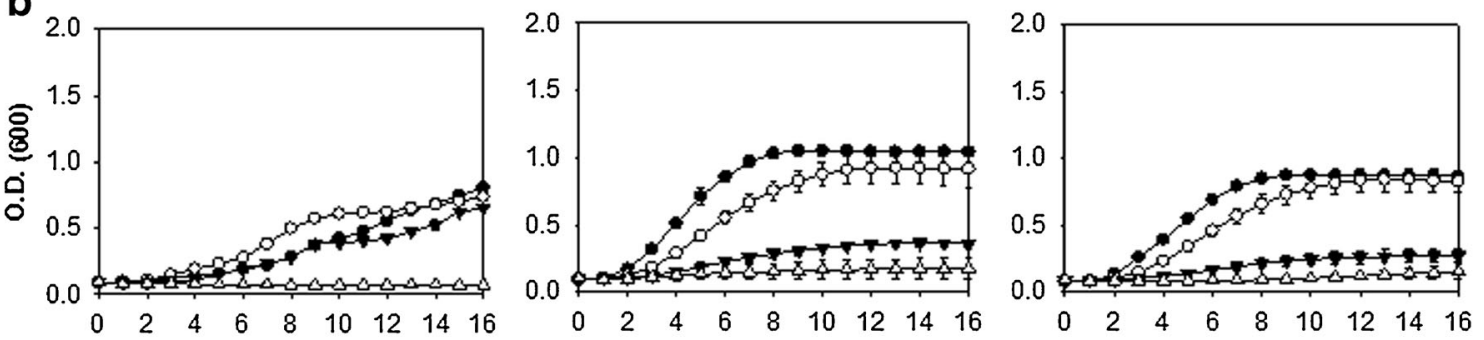

C

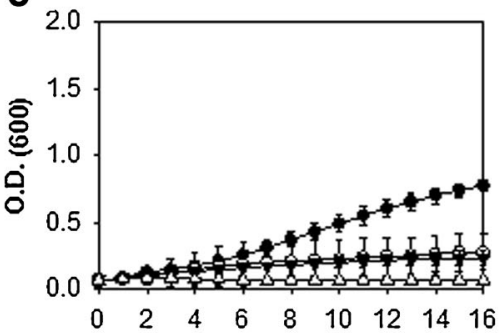

d

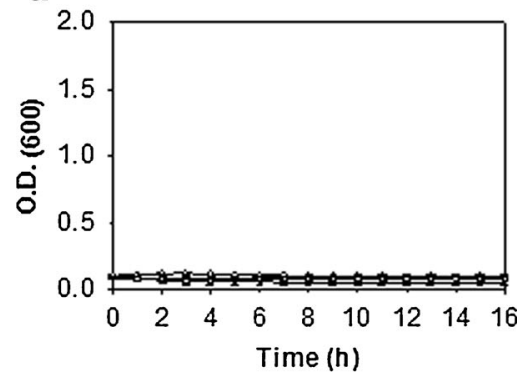

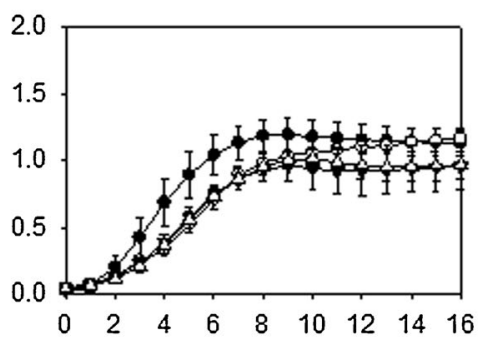
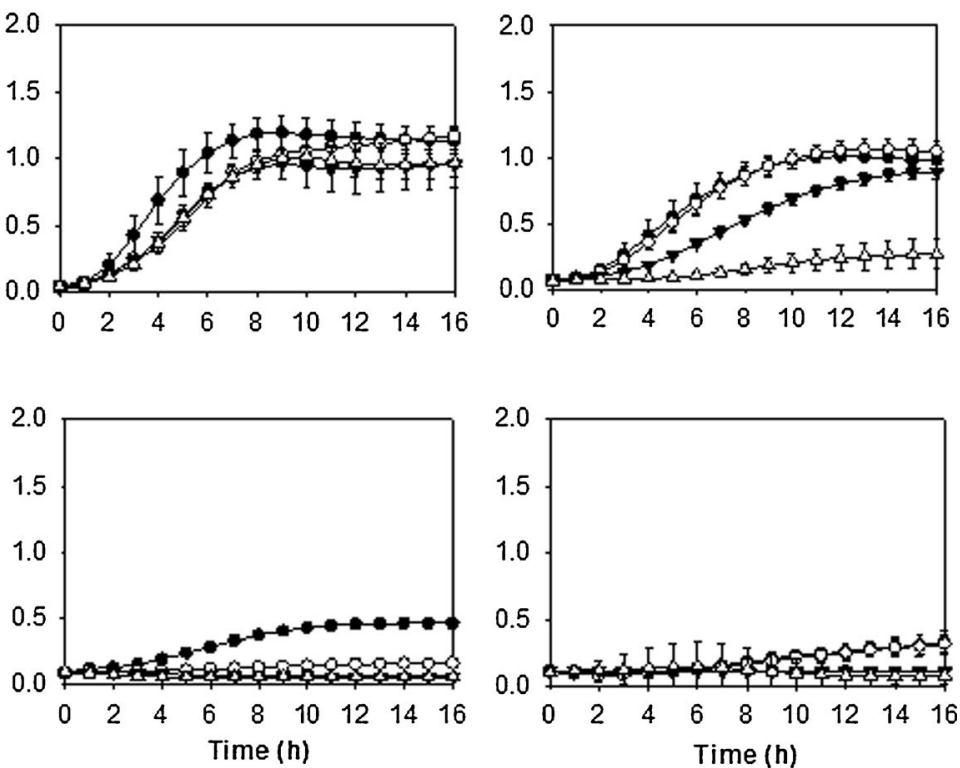

Fig. 4 Growth curves of $K$. marxianus strains as a function of varying temperature and ethanol concentrations in the liquid YP medium supplemented with $4 \%$ glucose $(\mathrm{v} / \mathrm{v})$. Each column represents a strain, UFV-3, ATCC 8554, and CCT 4086, as shown in the figure. Each line represents a specific growth temperature. a $30^{\circ} \mathrm{C}$. b $37^{\circ} \mathrm{C}$. c $42{ }^{\circ} \mathrm{C}$. d $45^{\circ} \mathrm{C}$. The symbols represent the concentration of ethanol added to the liquid culture medium: (black circle) $2 \%$ ethanol, (white circle) $4 \%$ ethanol, (black down-pointing triangle) $6 \%$ ethanol, and (white triangle) $8 \%$ ethanol against stresses is well documented in the literature for the disaccharide trehalose, but the protective effects of glucose have not yet been described. Thus, additional studies are needed to explain this phenomenon of acquiring temperature tolerance at high glucose concentrations. In assessing the specific growth rates, it was noticed that the $K$. marxianus strains had much higher values compared to $S$. cerevisiae strains (Table 4). K. marxianus yeast strains grew similarly to one another. These thermotolerance data were consistent with the literature because other $K$. marxianus strains have been reported to grow rapidly at temperatures above $40{ }^{\circ} \mathrm{C}$
(Fonseca et al. 2008; Rocha et al. 2011; Rodrussamee et al. 2011).

When evaluating growth in ethanol, $S$. cerevisiae strains were more tolerant $(8 \% \mathrm{v} / \mathrm{v})$ compared to $K$. marxianus strains $(4 \%$ v/v) (Figs. 3 and 4, respectively). S. cerevisiae showed less tolerance to ethanol at temperatures greater than $37{ }^{\circ} \mathrm{C}$ (Fig. 3). This effect may be due to the combination of temperature and ethanol stresses. High concentrations of ethanol can damage the cell wall, changing the permeability of the plasma membrane and the various transport systems, such as the glucose transport system. High temperatures can 
Table 5 Fermentation at 37 and $42^{\circ} \mathrm{C}$ with an initial O.D. $600 \mathrm{~nm}$ of 2 in $50 \mathrm{~mL}$ of fermentation medium supplemented with $4 \%(w /$ v) glucose

\begin{tabular}{|c|c|c|c|c|c|c|c|c|}
\hline \multirow[t]{2}{*}{ Yeast strain } & \multicolumn{2}{|c|}{ Initial glucose $\left(\mathrm{g} \mathrm{L}^{-1}\right)$} & \multicolumn{2}{|c|}{ Final glucose $\left(\mathrm{g} \mathrm{L}^{-1}\right)$} & \multicolumn{2}{|c|}{ Ethanol $\left(\mathrm{g} \mathrm{L}^{-1}\right)$} & \multicolumn{2}{|l|}{$\mathrm{Y}_{\mathrm{E} / \mathrm{G}}$} \\
\hline & $37^{\circ} \mathrm{C}$ & $42^{\circ} \mathrm{C}$ & $37^{\circ} \mathrm{C}$ & $42{ }^{\circ} \mathrm{C}$ & $37^{\circ} \mathrm{C}$ & $42{ }^{\circ} \mathrm{C}$ & $37^{\circ} \mathrm{C}$ & $42{ }^{\circ} \mathrm{C}$ \\
\hline LBM-1 & 47.00 & 47.00 & 0.04 & 10.35 & 21.70 & 10.64 & 0.46 & 0.29 \\
\hline CAT-1 & 47.00 & 47.00 & 0.00 & 9.82 & 22.77 & 9.92 & 0.48 & 0.27 \\
\hline PE-2 & 47.00 & 47.00 & 1.20 & 17.19 & 22.24 & 8.47 & 0.49 & 0.28 \\
\hline UFV-3 & 47.00 & 47.00 & 1.93 & 16.11 & 18.53 & 7.24 & 0.41 & 0.23 \\
\hline ATCC 8554 & 47.00 & 47.00 & 0.00 & 0.33 & 19.66 & 12.11 & 0.42 & 0.26 \\
\hline СCТ 4086 & 47.00 & 47.00 & 0.00 & 0.05 & 18.10 & 12.06 & 0.39 & 0.26 \\
\hline
\end{tabular}

damage the membrane and can cause protein denaturation and aggregation. Together, these factors inhibit growth and diminish the viability of the cultures (Ma and Liu 2010; Singer and Lindquist 1998).

K. marxianus and S. cerevisiae strains were evaluated for their capacities to ferment sugarcane bagasse via the simultaneous saccharification and fermentation process (Table 6). SSF tests at both $37{ }^{\circ} \mathrm{C}$ and $42{ }^{\circ} \mathrm{C}$ returned very similar $Y_{\mathrm{E} / \mathrm{C}}$ values. However, tests at $37{ }^{\circ} \mathrm{C}$ resulted in greater ethanol production than tests at $42{ }^{\circ} \mathrm{C}$, which could be related to the greater fermentative capacity of strains at the temperature $37^{\circ} \mathrm{C}$. In the presence of glucose, the concentration and yield of ethanol were higher at $37^{\circ} \mathrm{C}$ than at $42^{\circ} \mathrm{C}$, with yields close to the theoretical yields.

Upon analyzing the ethanol yields obtained (Table 6), it was noted that the values were similar to values already described in the literature for $S$. cerevisiae and $K$. marxianus isolates (De Souza et al. 2012; Santos et al. 2010). (Faga et al. 2010), using K. marxianus strains, obtained an ethanol concentration of approximately $19 \mathrm{~g} \mathrm{~L}^{-1}$ and an ethanol yield of 0.26 at $45^{\circ} \mathrm{C}$ using Panicum virgatum as substrate. In experiments conducted with the $S$. cerevisiae $\mathrm{D}_{5} \mathrm{~A}$ strain, concentration and yield were close to $14 \mathrm{~g} \mathrm{~L}^{-1}$ and $0.19 \mathrm{~g} \mathrm{~g}^{-1}$, respectively. (De Souza et al. 2012), using two of the strains used in this study, $K$. marxianus UFV-3 and $S$. cerevisiae LBM-1, obtained yields of $0.15 \mathrm{~g} \mathrm{~g}^{-1}$ for $S$. cerevisiae LBM- 1 at $37^{\circ} \mathrm{C}$ and $0.18 \mathrm{~g} \mathrm{~g}^{-1}$ for $K$. marxianus UFV-3 at $42{ }^{\circ} \mathrm{C}$. In this work, the same conditions previously used by
(De Souza et al. 2012) were used, but with a single change in the volume of medium to be fermented. The present work was performed with $50 \mathrm{~mL}$ fermentation medium, while (De Souza et al. 2012) used a volume of $30 \mathrm{~mL}$. Note that a larger volume of medium in Erlenmeyer flasks of the same volume favored the final yield of the SSF process. This effect may be related to the lower rate of evaporation and oxygen diffusion when using larger volumes of growth medium due to less agitation under these conditions. Comparing the yields obtained by Santos et al. (2010) with the yields obtained in this work, the importance of using thermotolerant yeast for the SSF process is highlighted.

In recent years, thermotolerant yeasts intended for use in SSF processes have been isolated and characterized. Some of these strains were able to ferment at $45{ }^{\circ} \mathrm{C}$. However, higher ethanol yields were obtained when the process was performed between 37 and $42{ }^{\circ} \mathrm{C}$. Above $40^{\circ} \mathrm{C}$, yeast viability decreases considerably, which affects ethanol production (Suryawati et al. 2008).

Among the yeast species known and used in fermentation processes, $K$. marxianus is the only one that is able to grow and ferment sugars at temperatures above $40^{\circ} \mathrm{C}$ (Abdel-Fattah et al. 2000; Ballesteros et al. 2004; De Souza et al. 2012; Hong et al. 2007; Nonklang et al. 2008; Singh et al. 1998; Suryawati et al. 2008). Among the advantages of using thermotolerant yeasts, one can cite reduced cooling costs, exemption from refrigeration units, better hydrolysis yields, reduced risks of contamination, and continuous evaporation of the broth under

Table $6 \mathrm{SSF}$ at 37 and $42{ }^{\circ} \mathrm{C}$ with an initial O.D. $600 \mathrm{~nm}$ of 2 in $50 \mathrm{~mL}$ of fermentation medium supplemented with $8 \%(w / v)$ sugarcane bagasse

\begin{tabular}{|c|c|c|c|c|c|c|c|c|}
\hline \multirow[t]{2}{*}{$\begin{array}{l}\text { Yeast strain/ } \\
\text { temperature }\end{array}$} & \multicolumn{2}{|c|}{$\begin{array}{l}\text { Initial glucose } \\
\left(\mathrm{g} \mathrm{L}^{-1}\right)\end{array}$} & \multicolumn{2}{|c|}{$\begin{array}{l}\text { Final ethanol } \\
\left(\mathrm{g} \mathrm{L}^{-1}\right)\end{array}$} & \multicolumn{2}{|c|}{$\begin{array}{l}Y_{\mathrm{E} / \mathrm{C}} \\
\text { (g ethanol/g cellulose) }\end{array}$} & \multicolumn{2}{|c|}{$\begin{array}{l}Y_{\mathrm{E} / \mathrm{G}} \\
\text { (g ethanol/g glucose) }\end{array}$} \\
\hline & $37^{\circ} \mathrm{C}$ & $42^{\circ} \mathrm{C}$ & $37^{\circ} \mathrm{C}$ & $42^{\circ} \mathrm{C}$ & $37^{\circ} \mathrm{C}$ & $42{ }^{\circ} \mathrm{C}$ & $37^{\circ} \mathrm{C}$ & $42{ }^{\circ} \mathrm{C}$ \\
\hline LBM-1 & 32.56 & 37.11 & 22.24 & 16.63 & 0.28 & 0.21 & 0.68 & 0.47 \\
\hline CAT-1 & 33.36 & 38.99 & 21.08 & 22.84 & 0.26 & 0.29 & 0.63 & 0.59 \\
\hline PE-2 & 32.93 & 37.30 & 19.43 & 20.31 & 0.24 & 0.25 & 0.59 & 0.54 \\
\hline UFV-3 & 36.64 & 32.60 & 22.62 & 16.12 & 0.28 & 0.20 & 0.62 & 0.51 \\
\hline ATCC 8554 & 35.38 & 41.03 & 22.32 & 16.95 & 0.28 & 0.21 & 0.63 & 0.43 \\
\hline CCT 4086 & 35.00 & 35.10 & 21.48 & 13.30 & 0.27 & 0.17 & 0.61 & 0.41 \\
\hline
\end{tabular}


reduced pressure (Hasunuma and Kondo 2012). Moreover, the use of industrial yeasts can facilitate the viability of the SSF process, as their stability in fermentation mash from different crops are known and they have been selected for their capacity to survive in industrial conditions and to compete with wild strains. The industrial S. cerevisiae strains CAT1 and PE-2 were selected from industrial processes and have been screened through a well-directed yeast selection program (Amorim et al. 2011; Basso et al. 2008). S. cerevisiae LBM-1 yeast shows thermotolerance, capacity for growth, and fermentation at $42{ }^{\circ} \mathrm{C}$, which are generally not found in yeasts belonging to the $S$. cerevisiae species; this strain shows promising use in industrial processes because it is wild and has not yet experienced selective industrial pressures. Future studies using $S$. cerevisiae LBM-1 shall aim to increase its tolerance to the stresses inherent in the ethanol production process and verify its stability in mash fermentation. Finally, results of this study demonstrated that industrial $S$. cerevisiae strains (CAT-1 and PE-2) have the potential to produce cellulosic ethanol, once they are able to produce similar ethanol yields to those of thermotolerant strains. In addition, the ethanol production from cellulosic biomass by $S$. cerevisiae CAT-1 in bioreactor was similar to that in Erlenmeyer flasks, indicating that this yeast is a good candidate to produce cellulosic ethanol on a large scale. The industrial strains are more tolerant to ethanol and have already been adapted to industrial conditions. Moreover, the study demonstrates that, although $K$. marxianus strains have fermentative capacities similar to $S$. cerevisiae strains, they have low ethanol tolerance, a characteristic that is an important target for enhancing the performance of this yeast in ethanol production.

Acknowledgments This research was supported by the Conselho Nacional de Desenvolvimento Científico e Tecnológico (CNPq), Fundação de Amparo a Pesquisa do Estado de Minas Gerais (FAPEMIG), and Coordenação de Aperfeiçoamento de Pessoal de Nível Superior (CAPES). Fermentec for providing the yeast strains $S$. cerevisiae CAT-1 and PE-2.

Open Access This article is distributed under the terms of the Creative Commons Attribution License which permits any use, distribution, and reproduction in any medium, provided the original author(s) and the source are credited.

\section{References}

Abdel-Banat BMA, Hoshida H, Ano A, Nonklang S, Akada R (2010) High-temperature fermentation: how can processes for ethanol production at high temperatures become superior to the traditional process using mesophilic yeast? Appl Microbiol Biotechnol 85: 861-867

Abdel-Fattah WR, Fadil M, Nigam P, Banat IM (2000) Isolation of thermotolerant ethanologenic yeasts and use of selected strains in industrial scale fermentation in an Egyptian distillery. Biotechnol Bioeng 68:531-535
Amorim HV, Lopes ML, de Castro Oliveira JV, Buckeridge MS, Goldman GH (2011) Scientific challenges of bioethanol production in Brazil. Appl Microbiol Biotechnol 91:1267-1275

Argueso JL, Carazzolle MF, Mieczkowski PA, Duarte FM, Netto OV, Missawa SK, Galzerani F, Costa GG, Vidal RO, Noronha MF, Dominska M, Andrietta MG, Andrietta SR, Cunha AF, Gomes LH, Tavares FC, Alcarde AR, Dietrich FS, McCusker JH, Petes TD, Pereira GA (2009) Genome structure of a Saccharomyces cerevisiae strain widely used in bioethanol production. Genome Res 19:2258-2270

Ballesteros M, Oliva JM, Negro MJ, Manzanares P, Ballesteros I (2004) Ethanol from lignocellulosic materials by a simultaneous saccharification and fermentation process (SFS) with Kluyveromyces marxianus CECT 10875. Process Biochem 39:1843-1848

Banat IM, Nigam P, Marchant R (1992) Isolation of thermotolerant, fermentative yeasts growing at $52^{\circ} \mathrm{C}$ and producing ethanol at $45^{\circ} \mathrm{C}$ and $50^{\circ} \mathrm{C}$. World J Microbiol Biotechnol 8:259-263

Banat IM, Nigam P, Singh D, Marchant R, McHale AP (1998) Review: ethanol production at elevated temperatures and alcohol concentrations: part I - yeasts in general. World J Microbiol Biotechnol 14: 809-821

Basso LC, de Amorim HV, de Oliveira AJ, Lopes ML (2008) Yeast selection for fuel ethanol production in Brazil. FEMS Yeast Res 8: $1155-1163$

Canilha L, Kumar Chandel A, dos Santos Milessi TS, Fernandes Antunes FA, da Costa Freitas WL, das Gracas Almeida Felipe M, da Silva SS (2012) Bioconversion of sugarcane biomass into ethanol: an overview about composition, pretreatment methods, detoxification of hydrolysates, enzymatic saccharification, and ethanol fermentation. J Biomed Biotechnol 2012:1-15

Causton HC, Ren B, Koh SS, Harbison CT, Kanin E, Jennings EG, Lee TI, True HL, Lander ES, Young RA (2001) Remodeling of yeast genome expression in response to environmental changes. Mol Biol Cell 12:323-337

Cortez LAB, Lora EES, Gómez EO (2008) Biomassa para bioenergia. UNICAMP, Campinas

De Souza CJ, Costa DA, Rodrigues MQ, dos Santos AF, Lopes MR, Abrantes AB, dos Santos CP, Silveira WB, Passos FM, Fietto LG (2012) The influence of presaccharification, fermentation temperature and yeast strain on ethanol production from sugarcane bagasse. Bioresour Technol 109:63-69

Diniz RH, Silveira WB, Fietto LG, Passos FM (2012) The high fermentative metabolism of Kluyveromyces marxianus UFV-3 relies on the increased expression of key lactose metabolic enzymes. Antonie Van Leeuwenhoek 101:541-550

Dos Santos VC, Bragança CR, Passos FJ, Passos FM (2013) Kinetics of growth and ethanol formation from a mix of glucose/xylose substrate by Kluyveromyces marxianus UFV-3. Antonie Van Leeuwenhoek 103:153-161

Faga BA, Wilkins MR, Banat IM (2010) Ethanol production through simultaneous saccharification and fermentation of switchgrass using Saccharomyces cerevisiae $\mathrm{D}(5) \mathrm{A}$ and thermotolerant Kluyveromyces marxianus IMB strains. Bioresour Technol 101: 2273-2279

Fonseca GG, Heinzle E, Wittmann C, Gombert AK (2008) The yeast Kluyveromyces marxianus and its biotechnological potential. Appl Microbiol Biotechnol 79:339-354

Hasunuma T, Kondo A (2012) Consolidated bioprocessing and simultaneous saccharification and fermentation of lignocellulose to ethanol with thermotolerant yeast strains. Process Biochem 47:1287-1294

Hong J, Wang Y, Kumagai H, Tamaki H (2007) Construction of thermotolerant yeast expressing thermostable cellulase genes. J Biotechnol 130:114-123

Koedritha P, Dubois E, Scherens B, Jacobs E, Boonchird C, Messenguy F (2008) Identification and characterization of a thermotolerant yeast strain isolated from banana leaves. ScienceAsia 34:147-152 
Krishna SH, Reddy TJ, Chowdary GV (2001) Simultaneous saccharification and fermentation of lignocellulosic wastes to ethanol using a thermotolerant yeast. Bioresour Technol 77: 193-196

Limtong S, Sringiew C, Yongmanitchai W (2007) Production of fuel ethanol at high temperature from sugar cane juice by a newly isolated Kluyveromyces marxianus. Bioresour Technol 98:33673374

Ma M, Liu ZL (2010) Mechanisms of ethanol tolerance in Saccharomyces cerevisiae. Appl Microbiol Biotechnol 87:829-845

Nevoigt E (2008) Progress in metabolic engineering of Saccharomyces cerevisiae. Microbiol Mol Biol Rev 72:379-412

Nonklang S, Abdel-Banat BM, Cha-aim K, Moonjai N, Hoshida H, Limtong S, Yamada M, Akada R (2008) High-temperature ethanol fermentation and transformation with linear DNA in the thermotolerant yeast Kluyveromyces marxianus DMKU3-1042. Appl Environ Microbiol 74:7514-7521

Ohta K, Wijeyaratne SC, Hayashida S (1988) Temperature-sensitive mutants of a thermotolerant yeast, Hansenula polymorpha. J Ferment Technol 66:455-459

Olofsson K, Bertilsson M, Liden G (2008) A short review on SSF - an interesting process option for ethanol production from lignocellulosic feedstocks. Biotechnology Biofuels 1:7

Olsson L, Soerensen HR, Dam BP, Christensen H, Krogh KM, Meyer AS (2006) Separate and simultaneous enzymatic hydrolysis and fermentation of wheat hemicellulose with recombinant xylose utilizing Saccharomyces cerevisiae. Appl Biochem Biotechnol 129-132: $117-129$

Rocha SN, Abrahao-Neto J, Gombert AK (2011) Physiological diversity within the Kluyveromyces marxianus species [corrected]. Antonie Van Leeuwenhoek 100:619-630

Rodrussamee N, Lertwattanasakul N, Hirata K, Suprayogi LS, Kosaka T, Yamada M (2011) Growth and ethanol fermentation ability on hexose and pentose sugars and glucose effect under various conditions in thermotolerant yeast Kluyveromyces marxianus. Appl Microbiol Biotechnol 90:1573-1586

Sanchez OJ, Cardona CA (2008) Trends in biotechnological production of fuel ethanol from different feedstocks. Bioresour Technol 99: $5270-5295$
Santos JRA, Souto-Maior AM, Gouveia ER (2010) Comparação entre processos em SHF e em SSF de bagaço de cana-de-açúcar para a produção de etanol por Saccharomyces cerevisiae. Quim Nova 33: 904-908

Silveira WB, Passos FJV, Mantovani HC, Passos FML (2005) Ethanol production from cheese whey permeate by Kluyveromyces marxianus UFV-3: A flux analysis of oxido-reductive metabolism as a function of lactose concentration and oxygen levels. Enzyme Microb Technol 36:930-936

Singer MA, Lindquist S (1998) Thermotolerance in Saccharomyces cerevisiae: the Yin and Yang of trehalose. Trends Biotechnol 16: 460-468

Singh D, Banat IM, Nigam P, Marchant R (1998) Industrial scale ethanol production using the thermotolerant yeast Kluyveromyces marxianus IMB3 in an Indian distillery. Biotechnol Lett 20:753-755

Soccol CR, Vandenberghe LP, Medeiros AB, Karp SG, Buckeridge M, Ramos LP, Pitarelo AP, Ferreira-Leitao V, Gottschalk LM, Ferrara MA, da Silva Bon EP, de Moraes LM, Araujo Jde A, Torres FA (2010) Bioethanol from lignocelluloses: Status and perspectives in Brazil. Bioresour Technol 101:4820-4825

Sun Y, Cheng J (2002) Hydrolysis of lignocellulosic materials for ethanol production: a review. Bioresour Technol 83:1-11

Suryawati L, Wilkins MR, Bellmer DD, Huhnke RL, Maness NO, Banat IM (2008) Simultaneous saccharification and fermentation of Kanlow switchgrass pretreated by hydrothermolysis using Kluyveromyces marxianus IMB4. Biotechnol Bioeng 101:894-902

Tomas-Pejo E, Garcia-Aparicio M, Negro MJ, Oliva JM, Ballesteros M (2009) Effect of different cellulase dosages on cell viability and ethanol production by Kluyveromyces marxianus in SSF processes. Bioresour Technol 100:890-895

Wilkins MR, Mueller M, Eichling S, Banat IM (2008) Fermentation of xylose by the thermotolerant yeast strains Kluyveromyces marxianus IMB2, IMB4, and IMB5 under anaerobic conditions. Process Biochem 43:346-350

Zakrzewska A, van Eikenhorst G, Burggraaff JE, Vis DJ, Hoefsloot H, Delneri D, Oliver SG, Brul S, Smits GJ (2011) Genome-wide analysis of yeast stress survival and tolerance acquisition to analyze the central trade-off between growth rate and cellular robustness. Mol Biol Cell 22:4435-4446 